\title{
The Dilemma of China Sci-tech Periodicals Lagging Behind the Rapid Development of Papers and the Win-Win Solutions
}

\author{
Zhang Chaojun ${ }^{1}$, Wang Hui ${ }^{1}$, Wei Wei ${ }^{1}$, Zhang Min ${ }^{1}$, Gao Rili ${ }^{1}$, Xiao Ying ${ }^{2}$, \\ ${ }^{1}$ Research Institute of Petroleum Exploration \& Development, Petrochina, Beijing, China \\ ${ }^{2}$ National Petroleum Reserve Center, Beijing, China
}

Email address:

zcj@petrochina.com.cn (Zhang Chaojun),birdxyzcj@163.com (Xiao Ying)

${ }^{*}$ Corresponding author

\section{To cite this article:}

Zhang Chaojun, Wang Hui, Wei Wei, Zhang Min, Gao Rili, Xiao Ying. The Dilemma of China Sci-tech Periodicals Lagging Behind the Rapid Development of Papers and the Win-Win Solutions. International Journal of Science, Technology and Society. Vol. 7, No. 1, 2019, pp. 14-20. doi: $10.11648 /$ j.ijsts.20190701.13

Received: November 5, 2018; Accepted: December 4, 2018; Published: March 25, 2019

\begin{abstract}
With the acceleration of scientific and technological progress in China, the number of scientific and technological papers published from China has soared, but the development of scientific and technological journals in China is relatively slow, and the problem that the development of periodicals lags behind the progress of science and technology and the growth of scientific and technological papers has become the focus of attention of Chinese scientific and periodical circles. In order to discover the way how to shorten the gap between scientific and technological innovation, rapid development of scientific and technological articles and slow development of scientific and technological journals in China, the authors studied and analyzed the problems and challenges encountered in the process of internationalization of Chinese scientific and technological journals based on the practice of academic journals, especially those of China petroleum industry in recent years. The authors put forword a set of strategies and experiences of developing sci-tech periodicals and science and technology at the same time. This paper reveals the deep-seated causes and negative effects of China sci-tech periodicals relatively lagging behind the rapid development of papers. The authors point out that well-known authoritative academic journals can increase the pace of internationalization on the basis of consolidating Chinese journals. According to the author's research, journals can give full play to the advantages of running journals in their mother tongue, stimulate the enthusiasm of scientists to create journals in their mother tongue, report on significant progress in scientific and technological innovation, carry forward the spirit of craftsmen, promote scientific editors, grasp academic trends, and promote the "four pairs" mode of running journals, so as to keep pace with the development of national science and technology. Synchronizely, sci-tech journals help national scientific and technological innovation, enhance the international influence of journals, and build the brand of authoritative academic journals. On this basis, multilingual publishing can even be launched for global scientific and technological dissemination.
\end{abstract}

Keywords: Sci-Tech Journals, Paper and Journals Upside-Down, Weak Journals and Strong Paper, Bilingual Journals in Chinese and English, Multilingual Publishing

\section{Introduction}

With the continuous advancement of China's national innovation strategy, scientific and technological innovation has received unprecedented attention. In recent years, China's $\mathrm{R} \& \mathrm{D}$ investment in science and technology has increased year by year, major scientific and technological advances and breakthroughs in various professions and industries have gradually increased. The output of scientific and technological articles has increased dramatically, and the growth rate of the number of academic papers has exceeded that of western developed countries such as Europe and the United States, ranking the top in the world. However, as a platform for science and technology communication and exchange, the development of science and technology journals lags behind, seriously restricting the right of 
academic discourse, the first issue of scientific and technological achievements and the industrialization of domestic scientific and technological achievements, which will ultimately affect the economic development of Chinese enterprises and even the country. How to make the scientists and technicians willing to write papers in Chinese scientific and technological journals and apply scientific and technological achievements to the economic development of their own country is an important issue that needs to be solved urgently by the scientific and technological journal circles. China science and technology periodicals shoulder the historical mission of promoting national science and technology innovation and leading the development of science and technology. After researching in recent years, some China science and technology periodicals have actively responded to challenges, constantly innovated and accumulated experience, and put forward a series of coping strategies and put them into practice. From Chinese-English bilingualism, going to "bilingual, bi-manuscript source, bi-directional translation and bilingual acquisition and compilation", a "four-pair" mode of running journals has been formed, which realizes the synchronization of petroleum scientific and technological progress with the development of journals. A win-win scheme is provided by the authors for the internationalization of authoritative academic journals in the industry and the industrialization of achievements in China and to provide reference for rapid development of the Chinese journals.

\section{The Upside Down Phenomenon of Articles and Journals and the Misplacement of Weak Journals and Strong Articles}

\subsection{The Phenomenon of Speeding up the Outflow of Papers}

Since the beginning of the 21 st century, the outflow of scientific papers in China has gradually attracted the attention of journals and academia [1-8]. According to the statistics of China Institute of Science and Technology Information, the number of papers published by Chinese authors in SCI journals increased year by year from 2000 to 2017, of which 31,000 were published in 2000 , and then increased year by year. In 2009, the number of papers increased to 126,000 , ranking second in the world. In 2016, the number of Chinese scientific and technological papers included in SCI database reached more than 360,000, an increase of nearly 25,000 compared with seven years ago. The number of papers and citations collected in 2016 are the second largest in the world, which indicates that the quantity of papers is large and the quality of papers is generally high.

JCR contains more than 8,000 journals. According to the country, the United States has the largest number of journals, with nearly 3,000, followed by the United Kingdom, with more than 1,500 journals, the Netherlands again, and about
700 journals [9-10]. In 2016, there were nearly 9,000 journals included in JCR, while only 185 journals in China, accounting for only $2 \%$, which was extremely inconsistent with $17.5 \%$ of the total number of papers. There was an upside-down phenomenon between large country of high SCI articles output and small country of low proportion of SCI journals (for short, the upside-down phenomenon of articles and periodicals). In the early 16 years of this century, the average growth rate of papers published in SCI journals in China was $15.8 \%$. In contrast, the number of Chinese sci-tech journals included in SCI database increased from 67 to 192 since 2001, with an average increase of only 7.3 in the middle of 17 years. After nearly 20 years, the digital growth rate of SCI journals in China is not matched, especially the base of SCI journals in China is very small, some journals even limit the number of publications, etc. On the contrary, the base of papers flowing abroad is large, and the growth rate is more than twice that of journals. The disparity between the number of SCI papers published in China and the number of SCI journals in China is growing. The number of SCI journals in China has been unable to meet China's demand for SCI journals published in this century, resulting in a serious upside-down phenomenon of articles and journals.

\subsection{The Development of Sci-Tech Periodicals Lags Behind the Rapid Growth of Papers and Its Negative Effects}

The upside-down phenomenon of articles and journals leads to the result that the development of sci-tech periodicals lags behind relatively. China's scientific and technological circles and periodical circles generally believe that China's scientific and technological level has made considerable progress, and the quality of scientific and technological papers has also improved rapidly, and both of them have developed rapidly almost simultaneously. However, as a channel and platform for dissemination of scientific papers, Chinese sci-tech periodicals have developed slowly, resulting in strong papers and weak periodicals. This paper calls them "strong articles and weak periodicals". Generally speaking, journals are strong when they have strong papers. The key problem at present is that many high-quality papers of China are lost abroad, which leads to the weakness of domestic journals. The upside-down of articles and journals reflects that the development of sci-tech periodicals lags behind the rapid growth of papers

Due to the slow increase in the number of domestic journal approvals and the small increase in the number of core journals, the growth rate of the number of papers published in core journals in China has been significantly smaller. According to the statistics in previous years, the growth rate was only about $6 \%$ (Fu Xiaoxia, 2013) [1]. Of course, due to the reasons of scientific research evaluation style, the exodus of high-quality papers is difficult to reverse in the short term. In addition, the total number of scientific and technological papers published in SCI and domestic core journals has reached more than 830,000 , and the number of domestic core journals can only accommodate more than half of them. 
According to the released data in 2018 [11], there were 2029 core journals in the field of natural sciences in 2017. A total of 472,300 papers were published by Chinese authors as the first authors, and the ratio of domestic to foreign papers was 5:4. Sci-tech periodicals are originally platforms for displaying and exchanging academic achievements, but it is difficult for domestic periodicals to form a strong attraction for excellent papers. The role of leading scientific and technological innovation is bound to gradually weaken. In turn, it is not conducive to the development of science and technology in China.

Publishing scientific and technological achievements in SCI journals is conducive to expanding the influence of Chinese scientists in international academic circles, increasing the weight of international exchanges, and playing an important role in enhancing the academic status of Chinese scientific and technological circles in the world. However, scientific papers are the carriers of research progress and achievements. The double barriers of non-native language creation and reading barriers will undoubtedly lead to difficulties in the transformation of achievements. On the contrary, it will help to improve the convenience of English-speaking countries to obtain the latest scientific and technological achievements of China in the first time. Considering the perspective of economic factors, the cost of publishing papers abroad and the cost of purchasing copyright abroad are also a huge expense. Another consequence of the upside-down phenomenon is that the quality of Chinese sci-tech journals will continue to weaken, and the development of journals will be constrained.

\subsection{The Reasons for the Gap Between the Slow Development of Scientific Journals and the Accelerated Development of Scientific and Technical Papers in China}

The siphon effect of SCI and Ei journals on Chinese scientific papers can not be neglected because of the change of evaluation mechanism of scientific research assessment style. In the process of development and internationalization of journals, there is no doubt whether they can be covered by SCI or Ei. Because the number of articles and periodicals is too large in the era of knowledge explosion, and international universities are facing the problem of whether they can be collected by SCI or Ei. Limited by funds, libraries of scientific research institutions will only choose those journals with high quality and influence, and SCI journals are usually the first choice. Whether they can be included in SCI has become the threshold for journals to be recognized by international academic circles.

As mentioned above, China has produced a large number of papers published in foreign journals, especially SCI journals, and the overall quality is good. However, the outflow of papers carrying high-level research results invisibly makes it more difficult to improve the academic quality of domestic journals. If the excellent papers are not totally published in overseas English journals, more than 400,000 or even more excellent papers will be published in domestic journals; the academic quality of domestic journals will inevitably rise with the content as the king. The first element of publication is innovation. If written in mother tongue, the author will write more brilliantly. Based on this thinking, the author believes that the main restrictive factors for the development of Chinese sci-tech periodicals are not entirely editorial skills. The most important is that the periodicals do not adapt to the development of national sci-tech and disciplines, or lag behind the speed of scientific and technological progress in the industry or disciplines, resulting in excellent research results and progress can not be published through domestic authoritative journals, which will ultimately lead to the weakening of the authority of journals in disciplines or industries. The publication of authoritative journals in China will eventually weaken the authority of journals in disciplines or industries.

\section{Strategies and Win-Win Solutions for Science and Technology Periodicals to Face Challenges}

The state attaches great importance to scientific and technological innovation, and the development of China's scientific and technological strength is an important opportunity and powerful driving force for the development of scientific and technological journals. In recent years, China has begun to realize the importance of science and technology communication platform and launched a series of measures to promote the development of science and technology journals, even explicitly requiring academicians candidates to publish a certain number of high-quality papers in domestic journals. There are 2029 kinds of science and technology core periodicals in China. Every periodical needs to be positioned accurately, select their espective different reader group and author group at first. Different objects of service will lead to different characteristics of periodicals and different paths of development.

With the increase of national investment in scientific and technological innovation, China's Petroleum Science and technology has made great progress, and petroleum science and technology journals have made considerable progress. Some academic leaders began to publish core achievements and excellent papers abroad. How to attract more high quality authors and high-quality manuscripts has also become a problem faced by petroleum journals. In the past 10 years, petroleum science and technology journals had given full play to its advantages in publishing in Chinese, actively cracked problems on the basis of the original ones, laid a solid foundation for publishing in Chinese at home, accumulated new experience, actively sought out and optimized schemes. Starting from bilingual Chinese and English, it has cooperated with western publishing groups and borrowed ships to sail to sea. First of all, it has issued an electronic version of English and translate the Chinese version partly. And then the full text of the paper was translated into English and then can probably be included in SCI or Ei. The 
introduction not only serves China's economic development with the latest scientific and technological achievements of the world's petroleum industry, but also sets up a global communication and exchange platform for Chinese scientists to go to the world, and at the same time forms a set of publication ideas and development strategies.

Admittedly, in recent years, some petroleum science and technology journals had made a series of significant progress. Presumably because it was included by Ei or SCI, however, from a deeper analysis, the author believes that being included by Ei or SCI is only a icing on the cake and can play a role in internationalization. On the contrary, it is precisely because of the solid foundation of running journals and the continuous innovation and improvement of the level of running journals that the journals have made great progress. Some petroleum sci-tech periodicals which are not included in Ei or SCI, also rank high in domestic periodicals, forming an authoritative group of periodicals in the petroleum industry. In fact, China's Petroleum Science and technology level has developed rapidly since this century, and petroleum journals are also facing the above challenges. Through analysis and research, the achievements of Petroleum Science and technology journals come from rich experience in running journals and industry influence, and take appropriate countermeasures to make petroleum science and technology periodicals develop synchronously with petroleum science and technology.

\subsection{High-Quality Manuscript Source Is the Basis for Sci-Tech Periodicals to Lead Innovation and Stable Development}

High quality manuscripts are the cornerstones of outstanding journals. Petroleum sci-tech periodicals insist on taking the initiative and conducting research in institutions so as to win high-quality manuscripts. In recent years, China's Petroleum Science and technology has made significant progress, and China's Petroleum Science and technology level has been in the forefront of the world. Striving for excellent manuscripts in China is the basis for the development of academic journals, and timely, rapid and high-quality dissemination of the latest scientific and technological progress is also an important way to promote the innovation of Petroleum Science and technology. Academic journals always take content as king, and the major research results are the basis of excellent papers. On the one hand, we should play the role of editorial committee, contacts with them in many ways, get through the contacts with major scientific research institutions, research teams of major projects and active top-level scholars, and obtain the latest developments in scientific and technological research and sources of papers; on the other hand, in order to train excellent editors and compete for more high-quality sources for periodicals, we should encourage journal editors actively go to oilfields, universities and institutions, timely grasp the development trends of academia and industry, timely follow-up, face to face with outstanding scientists and major project teams, in-depth know major breakthroughs of exploration and development, listen to scholars' research orientation and achievements of large-scale academic conferences, and academic achievements. The leader drew up the topic of the manuscript together, and obtained a large number of high-quality manuscripts. In recent years, there are almost every issue of great research achievements and great works led by elites in the academic circles. They timely report major breakthroughs and latest scientific and technological advances in the field of oil and gas exploration and development. They also guide major oil and gas discoveries and development of oil and gas fields in domestic and overseas cooperation zones, and promote the development and cultivation of journals. Raising talents, strengthening ties with academia, and taking part in academic conferences and investigating research institutions gradually become the mainstream. As soon as these papers reflecting major scientific and technological progress and research results were published, they quickly attracted great attention from academia and industry, and directly or indirectly promoted the development of science and technology in the upstream areas of the petroleum industry.

\subsection{Improving Editorial Quality and Creating Classic Papers with Craftsman Spirit}

The editing quality of periodicals is the basis for the development of periodicals, and is also the lifeline of the everlasting growth of journals. In recent years, the editorial office of journals has always insisted on carrying forward the spirit of craftsmen, rejecting inferior products, and striving to create classics. Editorial colleagues worked overtime and devoted a lot of effort to this. In 2017. Fine selection, gold rushing in the sand, and bearing huge workload have been ordinary state. Every manuscript has to go through more than 10 working procedures from manuscript to be published. It is exquisite and refined. The editorial office strives for perfection, makes bright spots more beautiful, eliminates errors, weakens defects, and strives to carve jade into fine works. After continuous fine polishing by editorial colleagues and repeated communication with the authors, most of the papers published have been widely concerned and fully recognized by the academic community and the general reader, and the editorial office was highly praised by the authors and their research teams at home and abroad. After the papers were published globally, many authors have also received invitations and requests for cooperation from various academic groups at home and abroad, and some of them have won various awards.

\subsection{Academic Editors Play an Important Role in the Development and Promotion of Scientific Journals}

The manuscripts in the field of petroleum upstream science and technology involve many disciplines, such as geoscience and petroleum engineering. Many contents are difficult to understand without certain professional knowledge, especially geological maps, which are very complicated. Simple text editor is not competent for editing scientific and 
technological papers. Therefore, the editorial office of petroleum science and technology periodicals focuse on the direction of scientific and technological editors, whether from the introduction of talents or post-training. The problems of manuscripts for petroleum science and technology always arise in different ways, some of which are professional problems, some of which are text content, some of which are graphs, etc. It can be said that minefields are not the same. Communication with authors is very important for editing work and an important means to improve the quality of paper editing. Communication requires a good professional foundation. Only high-level scientific editors can accomplish this work with high quality. At the same time, they can also bring inspiration to the author's scientific research work in the process and increase the influence of the journal.

\subsection{Writing Scientific and Technological Papers by Academic Editors Is Conducive to Improving the Academic Level of Editors}

Editors of petroleum sci-tech journals mostly come from the frontier of scientific research. There are long-term experiences for them in scientific research and a lot of experiences in publishing scientific and technological papers, which can well help them understand the thoughts of scientists and experts. After coming to the editorial office, they still insist on writing articles, tracking the development trends of industry and discipline, summarizing in time, and understanding the development of other journals by submitting papers. By writing papers of petroleum specialty and editing papers of publishing specialty, it is a good summary and promotion for editors. Deeper understanding and understanding of the frontiers of academia, smoother and deeper communication with scientists can provide better research and development and writing suggestions. It has received good feedback from industry experts. It has played a positive role in obtaining good reputation, more high-quality manuscripts and even directly promoting scientific and technological innovation. With the improvement of editors' summary, their scientific research level and editorial level have risen synchronously, and they have been recognized by the industry and invited to give lectures, which greatly improves the influence and recognition of journals, and at the same time makes great progress in personal career development.

\subsection{Segmenting Reader Community of Scientific and Technological Periodicals, Promoting Service Level and Maintaining the Sustainability of Periodicals Development}

Periodicals should serve the readers. Some domestic journals think that reader-centered thinking should be adopted [12-13], while others think that market-oriented thinking is wrong [14]. The authors believe that serving readers is a more appropriate formulation. Whether it must be reader-centered can be discussed, because it involves the problem of reader positioning. From the point of view of serving readers, it is not difficult to understand who periodicals should serve. If we serve Chinese readers, the scientific and technological circles and the industrial circles, we should first consider the reader's reading habits, reading convenience and so on. That is the authors' tend to focus on Chinese and English bilingual journals as the development path of journals. One of the values of periodicals is to make readers understand, understand well, not misunderstand, trust, inspire and benefit. After all, periodical papers ultimately allow readers to absorb, digest and promote the research results carried by the papers. Periodicals are obliged to provide readers with more, better and higher quality spiritual food. In addition, the editorial office of journals needs to provide high-quality editorial services for authors, and provide more convenient conditions and help for reviewing manuscripts for experts and scholars. These are the necessary conditions for the long-term, sustained and stable development of periodicals. Any closed-door publishing without understanding the feelings of readers, authors and scholars is short-sighted. petroleum science and technology periodicals adheres to the idea of opening its doors, serving its readers, authors and scholars, and has made a series of achievements.

\subsection{The Foundation of Running Periodicals in China Is the Preferential Conditions for Journals to Internationalize}

There are more than 40 core journals of petroleum science and technology. The sponsors of petroleum science and technology periodicals are mostly research institute with the strongest scientific research strength in there own field of the China petroleum industry. At the same time, there is a strong editorial committee, which is active in the academic frontier and can actively participate in the development of the journal. In addition, with the rapid improvement of China's petroleum science and technology level, journals continue to report major domestic and overseas scientific and technological achievements, and have made considerable progress. At the same time, it has established the status of authoritative academic journals in petroleum journals.

\subsection{Continuously Promote Internationalization and Informatization, and Form a Win-Win Mode of Running Journals}

Many excellent petroleum science and technology periodicals had been published in English, thus realizing the bilingual publishing mode of Chinese and English [15-17]. Since then, it has begun to solicit contributions globally, forming a bi-directional source of manuscripts at home and abroad. Through the continuous promotion of internationalization and electronic networking, journals have moved from bilingual Chinese and English to the "four-pair" mode of "bilingual, two-way translation, domestic and foreign sources of manuscripts, bilingual editing platform", and have come out of a win-win situation of academic internationalization, domestic 
industrialization of achievements, and overseas academic localization. It can be used for reference by China's sci-tech periodicals. At present, the way of internationalization of journals through bilingual starting in Chinese and English has been recognized by the journal circles with the test of Journal practice. About 130 kinds of English journals have been developed on the basis of Chinese journals of science and technology, such as Journal of Seismology et al[18-19]. Although there are still some problems to be solved in the development of bilingual journals, the sound development of many of the above journals shows that such a way of running journals is a feasible way.

\subsection{Constructing the Brand of Sci-Tech Periodicals Step by Step and Striving for the Synchronous Development with the Industry's Scientific and Technological Innovation}

With the increasing international influence of the petroleum science and technology periodicals, the number of foreign contributions has increased dramatically in recent years, with the largest increase in Europe and the United States. The readers have spread to most oil and gas producing countries and regions, such as the United States, Russia, France, the United Kingdom. The Journal built high-end scientific and technological exchanges and cooperation platform for the world's advanced petroleum theory and technology to enter China, China's petroleum industry scientific research achievements to the world. Petroleum science and technology periodicals have beem contributing to promoting the influence of Chinese scientific journals in the world academic circles and establishing the academic status of scientific journals.

\section{Conclusion}

With the rapid development of science and technology in China, the number of scientific and technological papers written and published in China has increased greatly, and the high-quality scientific and technological papers outflowing to the west is amazing. Scientific and technological progress and papers have strengthened, journal progress has been slow or even weakened, journal development and scientific and technological progress and scientific and technological papers have rapidly improved. The asynchronism has even caused a series of negative effects, such as "strong articles and weak publications", which have adversely affected China's scientific and technological innovation. Based on the experience and research of petroleum sci-tech journals, a set of strategies and practical cases of running petroleum Sci-tech Journals in China are given. It is proposed that the industry journals can give full play to the advantages of running domestic Chinese journals, start with bilingual Chinese and English, and stimulate the enthusiasm of scientists in their mother tongue. Major progress has been made in scientific and technological innovation. We should carry forward the spirit of craftsmen, promote scientific editing, track academic trends, promote bilingual, bi-directional source, bi-directional translation and bilingual editing of the "four pairs" mode of running journals, keep pace with the development of national science and technology, promote national scientific and technological innovation, enhance the international influence of journals, and build first-class international journal brand.

\section{Acknowledgements}

Senior engineer $\mathrm{Xu}$ Huaixian, Wang Darui, Wang Dongliang, senior editor Shan Dongbai, Song Lichen and all colleagues have given a lot of supports and assistances. We would like to express our thanks to them all.

\section{References}

[1] Fu Xiaoxia, You Suning, Li Guicun. The current situation and countermeasures of the outflow of excellent papers in China [J]. Acta Editologica, 2013, 25 (4): 325-328.

[2] Liu Daqian. A Brief Analysis of the Phenomenon of Outflow of Scientific and Technological papers in China [J]. Chinese Journal of Scientific and Technical Periodicals, 2008, 19 (6): 1057-1058.

[3] Wu Feng, He Feng. Historical evolution of outflow of excellent scientific and technological papers in China and its enlightenment to scientific and technological periodicals $[\mathrm{J}]$. Publishing and Distribution Research, 2013 (3): 75-78.

[4] Tao fan. Analysis of the outflow of scientific papers in China [J]. Acta Editologica, 2007 (04): 253-255.

[5] Su Xinning, Wang Dongbo. Reasons and Countermeasures for the rapid outflow of excellent academic papers in China [J]. Journal of Hehai University (Philosophy and Social Sciences Edition), 2016, 18 (04): 38-40+70+90.

[6] Song Hong. Attention should be paid to the outflow of high-level academic papers [J]. Chinese Journal of Scientific and Technical Periodicals, 2005, 16 (05): 736-739.

[7] Liu Liying, Wei Xiuju, Zhu Ming, et al. Composition and cause analysis of document economic loss of outflow of scientific and technological papers in China [J]. Acta Editologica, 2015, 27 (5): 426-428.

[8] Liu Liying, Wei Xiuju, Wang Liu, et al. Quantitative analysis of the outflow of outstanding scientific and technological papers in China from 2003 to 2012: Take the papers in the field of agricultural engineering as an example [J]. Chinese Journal of Scientific and Technical Periodicals, 2014, 25 (04): 478-484.

[9] Jia Jia, Pan Yuntao. Research on the distribution of top academic journals in various disciplines of powerful journals [J]. Acta Editologica, 2011, 23 (1): 91-94.

[10] Zhou Wen. Changes of Chinese journals included in SCI in recent years and their implications for the internationalization of journals [J]. Journal of Medical Informatics, 2007, 28 (3): 232-235.

[11] China Institute of Scientific and Technological Information. Statistics and analysis of Chinese scientific and technological papers in 2016 [J]. Science, 2017, 67 (6): 59-61. 
[12] Shiru, Huang Huifei. "Reader-centered" leads journal brand building [J]. Chinese Journal of Scientific and Technical Periodicals, 2009, 20 (01): 136-138.

[13] Guo Xiuting, Ning Zhijie, Xia Minying, et al. Seeking self-development of journals with reader as the center: "Journal of Orthopaedic Surgery in China" [J]. Acta Editologica, 2004 (04): 292-293.

[14] Su Liangyi. Taking the author as the main editor as the leading part: Questioning the "Reader-centered Journal Towards the Market" [J]. Acta Editologica, 1998 (03): 47-50.

[15] Song Lichen, Xu Huaixian, Wang Darui, et al. Coverage of PED by SCI and its implications for journal internationalization Coverage of PED by SCI and its implications for journal internationalization [J]. Acta Editologica, 2014, 26 (4): 383-385.
[16] Wang Darui, Xu Huaixian, Song Lichen, et al. Experience in running Petroleum Exploration and Development into SCI and EI databases to enhance the influence of sci-tech periodicals by going to sea by boat [J]. Chinese Journal of Scientific and Technical Periodicals, 2014, 25 (7): 963-965.

[17] Song Lichen. Active communication is an important link in the internationalization of scientific and technological journals --"Petroleum Exploration and Development (English Edition)" [J]. Science-Technology and Publication, 2013 (09): 44-46.

[18] Chen Zheng, Zhang Xin. Research on the cooperative development of Chinese and English sci-tech periodicals [J]. Acta Editologica, 2016, 28 (03): 217-219.

[19] Huang Feng, Huang Yayi, Xinliang. Enlightenment of bilingual publishing in Chinese and English on internationalization of Chinese sci-tech periodicals [J]. Chinese Journal of Scientific and Technical Periodicals, 2016, 27 (11): 1128-1132. 